\title{
PRINCIPAIS RAZÕES QUE MOTIVAM OS CANDIDATOS DE NÍVEL TÉCNICO A UMA VAGA NA PROFISSÃO DE ENFERMAGEM
}

\author{
Main reasons that motivate the candidates of technician level \\ to a vacant in the nursing profession \\ Principales razones que motivan los candidatos de nivel \\ técnico a un lugar en la profesión de enfermería
}

\author{
Dirce Stein Backes \\ Hedi C. Heckler de Siqueira
}

Marli T. Stein Backes

Alacoque Lorenzini Erdmann

\begin{abstract}
Resumo
Objetivamos com este estudo analisar as principais razões que motivam os candidatos, de nível técnico, a uma vaga na profissão de enfermagem, à luz das considerações da Teoria de Watson. 0 estudo foi realizado em um empreendimento da saúde, localizado na cidade de Pelotas, na Zona Sul do Estado do Rio Grande do Sul, entre os meses de setembro/2004 e fevereiro/2005, com a participação de 55 candidatos a uma vaga para atuar na referida instituição. Os relatos demonstraram que o "ambiente de cuidado" possuiu forte influência na escolha da profissão de enfermagem. Enquanto alguns mencionam a influência de algum familiar trabalhando na área, outros expressaram uma for te tendência de "ajudar o outro" e/ou se identificaram com a profissão ao acompanharem algum familiar no processo de internação hospitalar. Em suma, a expressão do cuidado como conhecimento específico e desejo de "ajudar os outros" pôde ser identificado entre os principais motivos.
\end{abstract}

Palavras-chave: Enfermagem. Motivação. Prestação de cuidados de saúde.

\begin{abstract}
We objectify with this study to evaluate the main reasons that motivate the candidates, of technician level, to a vacant in the nursing profession, according to the Watson Theory. The study was carried through in an enterprise of health, located in the city of Pelotas, in the South Zone of the State of Rio Grande do Sul, between the months september/ 2004 and february/2005, with the participation of 55 candidates to a vacant to act in the cited institution. The report had demonstrated that the "environment of care" has strong influence in the choice of the nursing profession. While some of them mention the influence of some relative working in the area, others had expressed one strong trend "to help the other" and/or they identified themselves with the profession when they escorted some relative in the process of hospital internment. In short, the expression of the care as specific knowledge and desire "to help the others" could be identified among the main reasons.
\end{abstract}

\section{Resumen}

Objetivamos con este estudio analizar las principales razones que motivan los candidatos, de nivel técnico, a un puesto en la profesión de enfermería, a la luz de las consideraciones de la Teoria de Watson. El estudio fué realizado en un emprendimiento de salud, ubicado en la ciudad de Pelotas, Zona Sur del Estado de Rio Grande do Sul, entre los meses de septiembre/2004 y febrero/2005, con la participación de 55 candidatos a un puesto para actuar en la referida institución. Los relatos demuestran que el "ambiente del cuidado" tuvo fuerte influencia en la elección de la profesión de enfermería. Mientras algunos mencionan la influencia de algún familiar trabajando en el área, otros expresaron una fuer te tendência de "ayudar al outro" y/o se identificaron con la profesión al acompañar algún familiar en el proceso de internación hospitalar. En suma, la expresión de cuidado como conocimiento específico y deseo de "ayuda los otros" puede ser identificado entre los principales motivos.
Keywords:

Nursing. Motivation. Delivery of health care.
Palabras clave:

Enfermería. Motivación. Prestación de atención de salud. 


\section{CONSIDERAÇÕESINICIAIS}

A escolha profissional, geralmente, traz consigo diversos conflitos porque a tomada de decisão envolve não apenas as aptidões, capacidades e aspirações do ser humano, mas, sobretudo os aspectos emocionais por tratar-se de um projeto de vida ${ }^{1}$. Além disso, as escolhas na maioria das vezes acontecem quando os jovens se encontram em grandes transformações físicas e psíquicas e são influenciados por pessoas próximas elou pelos meios de comunicação.

É de grande importância que a escolha profissional leve em consideração alguns critérios como: os atributos pessoais, a motivação, os valores predominantes, a polivalência da carreira, os aspectos psicológicos e 0 conceito que possui da profissão que deseja seguir.

Esse conceito, sendo claro, é capaz de auxiliar na tomada de decisão e trazer maior motivação e interesse pessoal e 0 desejo de seguir construindo 0 projeto de vida com base nas características dominantes dessa profissão. Logo, as características da enfermagem devem fazer parte da análise de quem deseja abraçar essa área de atuação, porque uma escolha inadequada poderá levar a uma desestruturação emocional e até mesmo existencial. ${ }^{1}$.

Sendo o cuidado com o ser humano a mola propulsora do ser e fazer enfermagem é interessante olhá-lo nesta concepção. 0 ser humano sempre foi dotado de atitudes de cuidado, seja na dimensão física, psíquica, social e/ou espiritual. A partir dessa compreensão, é possível encará-lo como "algo" inseparável do ser humano. Ao cuidar do outro, 0 profissional é motivado por uma força intrínseca, capaz de satisfazer o ego mais profundo de ir em busca do outro. Da mesma forma que sente a necessidade de ir em busca, também sente a necessidade de alguém que venha ao seu encontro. Nessa perspectiva, 0 cuidado supera a atitude materialista ou mecanicista e é identificado como sendo uma função de compartilhamento, de troca, com grande identificação com a atuação específica da enfermagem.

0 cuidado se manifesta no ser humano ainda antes de nascer, pois necessita de um "habitat" acolhedor, seguro, isto é, dotado de cuidados especiais. Ao nascer, geralmente, é confiado ao cuidado de pessoas especializadas, habilitadas para conduzir a primeira e grande ruptura do elo mais profundo entre mãe e filho. A seguir, as relações de cuidado se intensificam através dos pais, familiares, amigos, professores que, além do cuidado físico, se voltam para as necessidades mais íntimas de afeto, amor e calor humano.
0 cuidado, portanto, é produzido/reproduzido continuamente e de diferentes formas. 0 modo de ser cuidado revela, freqüentemente, a maneira concreta de ser e estar no mundo do ser humano. 0 profissional, ao realizar a sua opção pela enfermagem, opta por um cuidado específico e qualificado nas diferentes dimensões.

0 ser humano, através do cuidado, tem a capacidade privilegiada de interagir com a condição intersubjetiva do outro e descobrir-se um ser no mundo em constante sintonia com o outro, capaz de humanizar a sua essência. Ao agir dessa maneira, o profissional é capaz de colocar cuidado em tudo o que faz e projeta 2 . Conseqüentemente, é possível identificar o cuidado como um estar com o outro num processo de interrelacionamento, com possibilidade de desencadear um processo de mudança caracterizado pela troca, do dar e receber, buscando desenvolver o potencial humano.

Para compreender a real dimensão do cuidado em sua amplitude e profundidade, do ponto de vista existencial, o cuidado se acha a priori, antes de toda atitude e situação do ser humano, o que significa dizer que 0 mesmo se encontra na natureza e em toda atitude e situação de fato ${ }^{3}$. Percebe-se, assim, que 0 cuidado se encontra na essência do ser humano, no modo de ser essencial. Como essência da vida, passa pela dimensão física, psíquica, moral e espiritual. Numa compreensão ainda mais abrangente e complexa, configura-se o Sistema de Cuidados na Enfermagem, enfatizando que:

o cuidado (...) enquanto conteúdo ou essência da vida dos seres da natureza ou processo dinâmico produtor e protetor da vida configurado ora por pequenos atos/momentos e ora como atividade básica do profissional da enfermagem; ora como um misto de atividades de saúde e ora como um desencadeamento de medidas assistenciais, administrativas e legais, ora situado no mundo concreto e nos limites de uma estrutura organizacional, ora transcendendo ao controle objetivo real, extrapolando até mesmo as politicas sociais e as vontades individual ${ }^{4: 40}$.

0 cuidado, como conhecimento específico, vai muito além de um mero ato simbólico e/ou técnica prescritiva. Inserido num contexto formal ou informal, utiliza-se de diferentes modos, expressões e/ou significados para traduzir o que existe de mais humano naquele que é cuidado e/ou naquele que cuida.

Este raciocínio evoca os objetivos do cuidar que podem ser expressos como: 
(...) aliviar, confortar, ajudar, favorecer, promover, restabelecer, restaurar, dar e fazer. A cura pode ocorrer ou não, assim como a morte. 0 cuidado é imprescindível em todas as situações de enfermidades, incapacidade e durante o processo de morrer. Na ausência de alguma enfermidade e no cotidiano dos seres humanos, o cuidado humano também é imprescindível, tanto como uma forma de viver e de relacionar-se ${ }^{5: 129}$.

A amplitude expressa pela autora demonstra que 0 "cuidar" possui diversas dimensões e conotaçōes. Pode referir-se a cuidar das coisas, senti-las, respeitá-las ${ }^{3}$ como e, principalmente, cuidar do outro, estabelecendo o diálogo que constrói e produz energia, paz e amor, além do cuidado do corpo (na saúde ou doença) que implica cuidar da vida e tudo que a envolve.

A enfermagem ao cuidar do outro estabelece uma relação de ajuda autêntica, preocupando-se, envolvendo-se e dando conforto através da compreensão, solidariedade, da habilidade e competência técnico-científica do seu fazer.

0 cuidado, mais especificamente na profissão de enfermagem, pode ser considerado um evento especial/singular, marcado pela dinamicidade criativa do ser humano que cuida e/ou que é cuidado. Representa, também, a capacidade intrínseca de doarse, isto é, de estar a serviço do outro. Desse modo, objetiva-se analisar as principais razões que motivam os candidatos, de nível técnico, a uma vaga na profissão de enfermagem, à luz das considerações da Teoria de Watson.

\section{O CUIDADO SOB O OLHAR DE JEAN WATSON}

Uma teoria de enfermagem pode ser caracterizada a partir de um conjunto de conceitos, definiçōes e finalidades que apresentam uma forma sistemática de ver e perceber os fatores de conhecimento ${ }^{6}$. Entre as teorias de enfermagem, cujos autores dedicados e preocupados com o desenvolvimento e aperfeiçoamento da profissão de enfermagem, a teoria de Watson consolidou uma dimensão privilegiada, por contemplar e redefinir o cuidado não apenas como ato prescritivo/ normativo, mas por compreender 0 cuidado a partir de um ambiente de relaçoes que envolvem o cuidador, a pessoa cuidada, a família, 0 ambiente e a sociedade.

Watson, em sua teoria, defende o cuidado a partir de uma concepção holística, que passa a integrar todos os elementos num sistema de valores humanísticos, caracterizados pelo afeto, a escuta, a empatia, a autonomia e a liberdade de escolha.
O sentido de "cuidado" emerge a partir de um "ambiente de cuidado", onde tudo o que cerca/envolve o cuidador e/ou a pessoa a ser cuidada retrata uma perfeita harmonia de integração. Este princípio de cuidado parece, a partir de uma avaliação superficial, não ser tão simples, uma vez que na prática pode ser evidenciado um clima de desvalorização, desrespeito, insegurança e contínuas ameaças e incertezas, como conseqüência de um sistema de saúde defasado e em constantes crises, e/ou diante de uma cultura paternalista e burocratizada.

0 estudo sobre a interação no cuidado, discutido com o apoio dos conceitos da teoria de Watson, evidenciou que as interações no cuidado não se estabelecem de maneira puramente técnica, mas também através de uma abordagem expressiva no cuidar. Evidenciou ainda, que:

As qualidades humanas do profissional interferem na qualidade do cuidado, pois o que diferencia o cuidado técnico, baseado na habilidade e destreza manual, do cuidado humano é a capacidade do profissional em utilizar o 'coração', ou seja, sua emoção, e entender o cliente como ser humano único, que está em uma unidade hospitalar, dependendo de outras pessoas para se recuperar e resgatar nele a marca pessoal da sua subjetividade no que se refere aos cuidados que the são necessários e desejados ${ }^{7: 43}$.

Watson, através de sua refinada habilidade humana, fez emergir na enfermagem não apenas uma teoria, mas um sistema de valores humanísticos, que caracteriza o cuidado além do meramente palpável e idealista. Compreende-0, portanto, além do fator cura, ou seja, compreende o cuidado como processo de internalização que satisfaz a essência e as expectativas de vida do paciente.

Compreender o cuidado à luz de Watson, portanto, requer, na prática, uma habilidade que vai do biofísico, passando pelo intrapessoal, até alcançar a essência humana, ou seja, o espaço mais secreto do ser humano. Logo, o ser humano é uma pessoa valorizada em si mesma e para si mesma para ser cuidada, respeitada, compreendida e auxiliada ${ }^{8}$. 0 ser humano deve ser compreendido como maior diferente que a soma de suas partes. A incorporação de determinados valores antiéticos pela enfermagem, tem contribuído significativamente para a descaracterização do ambiente de cuidado humano. 


\section{METODOLOGIA}

0 estudo foi realizado em um empreendimento de saúde, localizado na cidade de Pelotas, na Zona Sul do Estado do Rio Grande do Sul, entre os meses de setembro/ 2004 e fevereiro/2005, com a participação aleatória de 55 candidatos a uma vaga para atuar na referida instituição.

Os questionamentos realizados, de forma informal e individual, no momento da entrevista seletiva, com dia e horário previamente agendados, consistiram, basicamente, nas seguintes questões: 0 que motivou a sua escolha profissional? 0 que você entende por cuidado, hoje? Os dados foram tratados, observando os seguintes passos: organização dos dados coletados; leitura e releitura do material, com retomada à questão problema e os objetivos do estudo e contato exaustivo com o referencial teórico ${ }^{9}$. Assim, apresentamos categorias predominantes que emergiram a partir dos apontamentos durante a entrevista, ilustrados com falas significativas dos candidatos participantes do estudo identificados com a letra e seguidos de um algarismo de um a 55 (E1, E2, E3...).

A metodologia de trabalho propriamente dita foi balizada pela análise e compreensão dos fatores de cuidado idealizados por Watson para a conquista de um cuidado humano, que constrói o cuidado de enfermagem sobre dez fatores $s^{8: 75}$.

Para atender os critérios éticos, foram seguidas as recomendações da Resolução №. 196/96, do Conselho Nacional de Saúde, bem como a solicitação de autorização ao Comitê de Ética em Pesquisa da Santa Casa de Misericórdia de Pelotas, a fim de validar a proposta de trabalho e poder divulgar as informações. Os participantes que responderam afirmativamente ao convite foram esclarecidos sobre os objetivos e a metodologia do estudo, bem como solicitado o Consentimento Livre e Esclarecido e assegurado 0 direito de acesso aos dados e garantia que a identidade seria mantida em sigilo.

\section{ANÁLISE E COMPREENSÃO DOS SIGNIFICADOS ATRIBUÍDOS PELOS PROFISSIONAIS}

Watson considera o cuidado o atributo mais valioso que a enfermagem tem para oferecer à humanidade. Corroborando a idéia, um dos candidatos mencionou:

o cuidado, para mim, é um dom especial confiado especialmente para alguns profissionais e por gostar de cuidar de pessoas me senti atraída para a enfermagem (E8).
0 cuidado de enfermagem, todavia, parece estar ameaçado pelo uso exagerado de tecnologias, pelas ordens prescritivas e pela burocratização das atividades. Ao defender o cuidado humano, Watson enfatiza também, 0 cuidado que satisfaz a essêncialalma, motivo pelos quais inúmeros profissionais de enfermagem ingressaram na profissão.

Fiz enfermagem por que sempre me senti bem ajudando as pessoas.(E1, E3, E6, E11, E12); sentia uma sensação interior de confor to e bem-estar muito forte ao cuidar de um familiar doente (E21, E32).

Watson dá ênfase ao cuidado global - holístico. Um cuidado, portanto, que não se limita à condição física, mas que exige do profissional desvelo, atenção e que requer, de acordo com um dos relatos:

\section{(...) coragem de quebrar rotinas burocratizadas (E19).}

Durante séculos, milhares de religiosos dedicaram tempo e vida ao cuidado dos doentes, praticamente sem recompensa terrestre além do parco sustento, senão a convicção íntima de fazer bem o seu dever, de realizar a sua vocação e seu ideal representada no cuidado que satisfizesse a alma/essência. Logo, o foco de atenção concentrava-se no bem-estar global da pessoa, isto é, a tendência era levar em consideração não somente o cuidado físico, mas, também, o cuidado psicológico, 0 social e 0 espiritual do paciente ${ }^{10,11}$.

A relação de cuidado não é de "domínio sobre", mas de convivência, de empatia, de solidariedade e não pura intervenção técnica ${ }^{3}$. Logo, cuidar é entrar em sintonia com o eu mais profundo, com a singularidade e essência da pessoa humana. Em consonância com a idéia, alguns candidatos fizeram o seguinte comentário:

Quando cuido de um doente, eu procuro desempenhar bem a técnica, mas também acho essencial uma palavra de ânimo, de conforto que instila fé para superar as dores (E17, E32).

Eu busquei o curso de enfermagem porque entendo que posso realizar algo mais profundo pelos outros (E28).

Sinto que muitas vezes uma palavra de conforto e um carinho valem mais que um remédio (E33, E37, E45).

Percebo que ao ajudar o outro me sinto mais feliz. Sinto-me bem, confortado. (E49).

0 cuidado deve ser entendido como um dever de cada pessoa, e não um dever exclusivo de uma classe profissional. Existir é fazer parte e identificar-se com 
uma comunidade formada por pessoas significativas. Nesse sentido, o cuidado requer, essencialmente, a capacidade de detectar, sentir e interagir com a necessidade humana ${ }^{12,13}$.

Cuidar, para mim, é saber escutar, sorrir e dar carinho (E23).

(...) a gente sempre cuida. Claro, antes não tinha um preparo maior. Mas todas as famílias acabam cuidando e cuidado bem (E42).

0 cuidado gera no profissional um movimento que vai muito além da relação cuidador-doente. 0 mesmo pode ser identificado nas diferentes relações/conexões que 0 ser humano estabelece no seu dia-a-dia. 0 poder de transformar pelo amor, pela paixão e pelo cuidado não são dons especiais de nenhuma seleta minoria ${ }^{12}$, mas de todos quantos se relacionam e/ou estabelecem relações recíprocas de empatia, solidariedade e ajuda mútua.

Á luz de Watson, é possível alcançar a dimensão mais profunda e essencial do cuidado, isto é, o cuidado intersubjetivo, que não requer mágicas extraordinárias, apenas 0 amor como forma de cuidado relacionado à alma. É preciso compreender, todavia, que por muitos anos se perpetuou na enfermagem uma idéia fragmentada e reducionista de cuidado como se estivesse associado apenas à condição física e, ainda, como se o único responsável pelo cuidado capaz de satisfazer a alma/essência seria o religioso.

Ao cuidar do outro, o profissional é motivado por uma força intrínseca, capaz de satisfazer o seu ego mais profundo, de ir à busca do outro, como refere a fala:

Eu me sinto extremamente satisfeita em poder cuidar e auxiliar o outro em sua doença. Parece que me realizo e cresço mais como pessoa (E42).

Logo, sentimos a necessidade de ir à busca e/ou, em algum momento sentimos a necessidade de alguém que venha ao nosso encontro. Assim, 0 cuidado supera a atitude materialista e/ou reducionista da prática dos profissionais ${ }^{6}$.

Atualmente, parece haver uma crescente preocupação com a dimensão do cuidado relacionada à alma, ou seja, relacionada à essência humana. Na concepção de Watson, o cuidado humano e o cuidado relacionado à alma encontram-se intimamente relacionados, podendo ser considerados elementos importantes no processo holístico. Pequenos detalhes podem fazer a diferença quando nos referimos ao cuidado.
O cuidado, ao contrário do que muitos pensam, não se traduz num ato de fazer ou que demande muito tempo para exercê-lo. o cuidado requer que se faça bem feito, ou seja, com especial atenção tudo aquilo que fazemos como: bater à porta ao entrar no quarto do paciente; chamar - paciente pelo nome; informar os procedimentos a serem realizados (E33).

Essas atitudes eu pude observar durante a internação de um familiar no hospital. A gente ficava atento a tudo o tempo todo. Parece que a gente fica mais sensível a tudo o que acontece $(E 33, E 38, E 42)$.

Ao refletir sobre o cuidado, hoje, é preciso considerar, igualmente, a essência do ser, o respeito à individualidade e a necessidade da construção de um espaço concreto nas instituições de saúde que legitimem o humano das pessoas envolvidas ${ }^{2}$. Logo, 0 cuidado integradolintegrador deve ser considerado premissa indispensável no ser e fazer enfermagem. É notório, portanto, que o cuidado conquistou espaço e reconhecimento crescente no campo da saúde, a partir das políticas e programas de humanização da assistência.

0 cuidado relacionado à essência humana, antes considerado vital no processo de cura dos pacientes, agora demanda raciocínio científico. Com isso, os profissionais de enfermagem parecem ter perdido a sensibilidade, as percepções afetivas, as fortes emoções, enfim, 0 respeito à vida.

Em suma, ao analisar a ciência do cuidado, é possível afirmar que 0 alcance do cuidado vai muito além do biofísico. 0 que de fato parece estar em evidência, hoje, e que intenta estimular os profissionais, é a alta tecnologia - como foco principal, e não mais o paciente. Watson reforça este referencial quando enfatiza que 0 cuidado humano está cada vez mais ameaçado pela desenvolvida tecnologia e pelas restrições burocráticas e administrativas das instituições ${ }^{8}$.

\section{CONSIDERAÇÕES FINAIS}

o estudo buscou colocar em evidência a importância do "cuidado" como conhecimento específico e como instrumento de "ajuda ao outro" apresentado entre as razões que motivam os candidatos, de nível técnico, a uma vaga nos serviços de enfermagem e 0 ambiente de cuidado como elemento facilitador na consolidação do ideal. 
0 cuidado como essência da vida perpassa desde os pequenos atos do pensar, do ser, do fazer, e até a configuração de um processo de cuidar que envolve tanto 0 ser cuidado, quanto o cuidador. Não importam, nesse momento, os significados/conotações atribuídos ao cuidado, mas a ênfase dada pelos candidatos como elemento motivador para o critério da escolha profissional e para a realização da profissão. Importa que o cuidado, na sua forma mais original, prima pela essência do ser humano como um ser único, indivisível, autônomo e com liberdade de escolha, isto é, na compreensão do ser humano como um ser integral.

A ênfase dada ao cuidado intersubjetivo é premissa básica para que a interação transcenda a dimensão puramente física e material. A sensibilidade e a interação são, portanto, capazes de perceber no fazer ao outro (doente) a capacidade de experimentar sentimentos de ternura, de compaixão e sentir emoções, características elementares para 0 desempenho das relações satisfatórias.

Os candidatos, ao expressarem as suas idéias a respeito do cuidado, demonstraram que a escolha da sua profissão está alicerçada em critérios que enfatizam não apenas os conceitos de sua área profissional, mas também em atributos pessoais, nos aspectos psicológicos e especialmente na motivação.

Em suma, o "cuidado", mesmo ameaçado pelas exigências burocráticas e tecnológicas, permanece na origem da profissão de enfermagem, 0 que deve ser considerado um fator altamente positivo e animador para os profissionais, principalmente em tempos em que a temática da humanização ganhou espaço privilegiado.

\section{Referências}

1. Mello FAF. O desafio da escolha profissional. São Paulo (SP): Papirus; 2002.

2. Pessini L. Humanização em saúde: 0 resgate do ser com competência científica. 0 Mundo da Saúde 2003 abr/jun; 27(02): 203-5.

3. Boof L. Saber cuidar. Petrópolis (RJ): Vozes; 1999.

4. Erdmann AL. Sistema de cuidados de enfermagem. Pelotas (RS): Universitária/UFPel; 1996.

5. Waldow VR. Cuidado humano: resgate necessário. Porto Alegre (RS): Sagra Luzzato; 1999.

6. George J. Teorias de enfermagem: os fundamentos a prática profissional. $4^{\text {a }}$ ed. Porto Alegre (RS): Artes Médicas; 2000.

7. Castro ES, Mendes PW Ferreira MA. A interação no cuidado: uma questão na enfermagem fundamental. Esc Anna Nery RevEnferm 2005 abr; 9 (1):39-45.

8. Watson J. Nursing: The philosophy and science of caring. Boston (USA): Little Brown; 1979.

9. Minayo MCS. Desafio do conhecimento. 5a ed. São Paulo (SP): Hucitec-Abrasco, 2000.

10. Lepargneur $H$. Procurando fundamentos para a humanização hospitalar. 0 Mundo da Saúde 2003 abr/jun; 27(02): 219-30.

11. Pessini L, Bertachini L. Humanização da dor e do sofrimento humanos na área da saúde. In: paliativos. São Paulo (SP): Loyola; 2004. p.11-30.

12. Silva MJP.Oamoréo caminho: maneiras de cuidar.São Paulo (SP):Gente; 2000.

13. Backes DS. Estratégias de humanização do cuidado no Centro de Terapia Intensiva. Santa Maria (RS): SEFAS; 2004.

\section{Sobre as Autoras}

\section{Dirce Stein Backes}

Chefe do Serviço de Enfermagem da Santa Casa de Misericórdia de Pelotas RS; Mestre em Enfermagem pela Fundação Universidade Federal do Rio Grande FURG Doutoranda em Enfermagem no PENUFSC e Membro do GEPADES-UFSC. E-mail: backesdirce@ ig.com.br

\section{Marli T. Stein Backes}

Enfermeira no Hospital Escola da Universidade Federal de Pelotas RS; Mestre em Enfermagem pela Fundação Universidade Federal do Rio Grande FURG. E-mail: marli.backes@ bol.com.br

\section{Hedi C. Heckler de Siqueira}

Professora do Programa de Pós-graduação do Curso de Mestrado em Enfermagem da Fundação Universidade Federal do Rio Grande RS; Doutora em Enfermagem pela Universidade Federal de Santa Catarina UFSC. Membro do Grupo de Estudos e Pesquisas em Enfermagem/Saúde (NEPES). E-mail: hedihs@ terra.com.br

\section{Alacoque Lorenzini Erdmann}

Professora Titular do Departamento de Enfermagem da Universidade Federal de Santa Catarina, Docente do PEN-UFSC. Doutora em Filosofia da Enfermagem pela PEN-UFSC. Pesquisadora e Representante da Área de Enfermagem no CNP q. Coordenadora do Grupo de Estudos e Pesquisas em Administração de Enfermagem e Saúde GEPADES-UFSC. E-mail: alacoque@ newsite.com.br 